\title{
Fermi Level Position at Metal-Semiconductor Interfaces*
}

\author{
C. A. MEAD \\ California Institute of Technology, Pasadena, California \\ AND \\ W. G. Spitzer \\ Electrical Engineering Department, University of Southern California, Los Angeles, California \\ (Received 18 November 1963; revised manuscript received 16 January 1964)
}

\begin{abstract}
The position of the Fermi level at a metal-semiconductor interface relative to the conduction band has been found to be a constant fraction of the semiconductor band gap for all but 3 of the 14 group IV or III-V semiconductors studied. In all cases, the position was essentially independent of the metal work function. This general result is not inconsistent with the limited theories of surface state energies now available. The three exceptional cases can be understood in terms of a first-order perturbation to the surface state energies correlated with a similar perturbation observed in the energy gap at the (111) zone edge. Experiments are also reported on $\mathrm{Ga}$ (As-P) alloys, and two II-VI materials showing distinctly different behavior.
\end{abstract}

\section{INTRODUCTION}

$\mathbf{R}^{\mathrm{H}}$ ECENT experimental work ${ }^{1}$ has drawn attention to some interesting systematic relations in the Schottky barriers involved in metal-semiconductor interfaces. One of the striking features of such barriers on group IV and III-V semiconductors is that, aside from small systematic variations previously noted, ${ }^{2}$ the barrier height is nearly independent of the work function of the metal. A second feature is that the Fermi level at the interface is fixed the same fraction of the band gap above the valence band edge for six semiconductors, while large deviations from this general behavior were noted for three others.

In the present work, similar results are reported for a number of additional materials all of which follow the general behavior described above. The three materials which show deviations in the measured barrier heights and hence surface state energies are discussed in terms of an empirical relation with the first-order shift in the (111) band gap.

Experimental techniques used in this study have been described previously. ${ }^{1,2}$ In the case of $\mathrm{CdS}$ where the barrier height is strongly dependent on the metal work function, it was reported ${ }^{2}$ that the results are sensitive to the semiconductor surface preparation, and vacuum cleavage was found to be a desirable technique. In all group IV and III-V samples, where both vacuum cleavage and chemical preparation could be employed (seven different materials), the barrier height measurements showed no appreciable dependence on the method of surface preparation. Two exceptions are AlAs and $\mathrm{AlSb}$ which react rapidly with water in the atmosphere, and hence the vacuum cleavage technique was essential. ${ }^{3}$ Available samples of diamond, $\mathrm{BP}, \mathrm{BN}$, and $\mathrm{GaP}$ were so small that cleavage could not be employed.

\footnotetext{
* Supported by the U. S. Office of Naval Research, the Technical Advisory Committee of the Joint Services Electronic Program, and the International Telephone and Telegraph Company.

1 C. A. Mead and W. G. Spitzer, Phys. Rev. Letters 10, 471 (1963).

${ }^{2}$ W. G. Spitzer and C. A. Mead, J. Appl. Phys. 34, 3061 (1963).

3 C. A. Mead and W. G. Spitzer, Phys. Rev. Letters 11, 358 (1963).
}

In many cases the reverse-leakage current of vacuumcleaved samples was substantially higher than that for similar units prepared on chemically polished surfaces, and hence the barrier heights of the latter could be determined with greater accuracy.

A summary of the data for all materials studied to date is given in Table I. In addition to those mentioned in the table, a large number of samples were studied; however, the data obtained were not considered sufficiently accurate to be included in the tabulated values. Of a total of 14 different semiconductor materials of the diamond group IV or zincblende III-V types with band gaps covering a factor of 40 in energy, all but three exhibit a Fermi level at the interface fixed very close to $E_{g} / 3$ from the valence-band edge. In every case, two (usually $\mathrm{Au}$ and $\mathrm{Al}$ ) or more metals of widely different work functions were used. Specific checks for dependence of barrier height on metal work function were often made by comparison of the I-V characteristics. While this measurement may not yield an accurate value for the barrier, for any given semiconductor it provides a simple method for evaluating the relative barrier heights for different metals. In no case did the barrier height depend appreciably on the metallic element or the doping of the semiconductor.

Because of the very different behavior of CdS from the other materials, it is of considerable interest to note the behavior of CdTe, a II-VI compound with zincblende structure. Unlike $\mathrm{CdS}$, this material exhibits barriers which are substantially independent of the metal, but whose magnitude is not the same fraction of the band gap as in the other zincblende materials.

Measurements were also made on $\mathrm{Ga}\left(\mathrm{As}_{1-x} \mathrm{P}_{x}\right)$ solid solutions in which continuous variation in band gap between the GaAs and $\mathrm{GaP}$ values is possible. Within a rather large scatter of the experimental data, the points are consistent with $\varphi_{B p}=E_{g} / 3$ (using the notation of Ref. 2) in both the indirect and direct gap regions, ${ }^{4}$

${ }^{4}$ W. G. Spitzer and C. A. Mead, Phys. Rev. 133, A872 (1964). 
TABLE I. Barrier heights on semiconductors measured to date. The values determined by the voltage variation of the capacitance (labeled $I / C^{2}$ ) have been corrected for Fermi energy. Energies are measured from valence band edge on $p$-type samples and conduction band on $n$ type.

\begin{tabular}{|c|c|c|c|c|c|c|c|}
\hline \multirow[b]{2}{*}{ Semiconductor } & \multirow[b]{2}{*}{ Type } & \multirow[b]{2}{*}{$\begin{array}{l}\text { Metal } \\
\text { layer }\end{array}$} & \multirow[b]{2}{*}{$\begin{array}{c}\text { Tempera- } \\
\text { ture } \\
\left({ }^{\circ} \mathrm{K}\right)\end{array}$} & \multicolumn{2}{|c|}{ Photoresponse } & \multirow[b]{2}{*}{$\begin{array}{l}\text { Number } \\
\text { of } \\
\text { samples }\end{array}$} & \multirow{2}{*}{$\begin{array}{l}/ C^{2} \\
\quad \begin{array}{l}\text { Barrier } \\
\text { height }\end{array}\end{array}$} \\
\hline & & & & $\begin{array}{l}\text { Number } \\
\text { of } \\
\text { samples }\end{array}$ & $\begin{array}{l}\text { Barrier } \\
\text { height }\end{array}$ & & \\
\hline $\mathrm{CdS}$ & $\begin{array}{l}n \\
n \\
n \\
n \\
n \\
n\end{array}$ & $\begin{array}{l}\mathrm{Au} \\
\mathrm{Cu} \\
\mathrm{Ni} \\
\mathrm{Al} \\
\mathrm{Ag} \\
\mathrm{Pt}\end{array}$ & $\begin{array}{l}300 \\
300 \\
300 \\
300,77 \\
300 \\
300\end{array}$ & $\begin{array}{l}9 \\
2 \\
1 \\
3 \\
3 \\
3\end{array}$ & $\begin{array}{l}\quad 0.78 \pm 0.03 \\
0.36 \\
0.45 \\
\quad \text { ohmic conta } \\
0.56 \pm 0.02 \\
0.85 \pm 0.03\end{array}$ & $\begin{array}{l}5 \\
2\end{array}$ & $\begin{array}{l}0.80 \pm 0.05 \\
0.35 \pm 0.03\end{array}$ \\
\hline GaAs & $\begin{array}{l}n \\
n \\
n \\
n \\
n \\
n \\
n \\
p \\
p \\
p \\
p \\
p \\
p \\
p\end{array}$ & $\begin{array}{l}\mathrm{Au} \\
\mathrm{Pt} \\
\mathrm{Be} \\
\mathrm{Ag} \\
\mathrm{Cu} \\
\mathrm{Al} \\
\mathrm{Al} \\
\mathrm{Au} \\
\mathrm{Au} \\
\mathrm{Pt} \\
\mathrm{Ag} \\
\mathrm{Cu} \\
\mathrm{Al} \\
\mathrm{Al}\end{array}$ & $\begin{array}{r}300 \\
300 \\
300 \\
300 \\
300 \\
300 \\
77 \\
300 \\
77 \\
77 \\
77 \\
77 \\
300 \\
77\end{array}$ & $\begin{array}{l}1 \\
4 \\
2 \\
2 \\
5 \\
2 \\
\\
2\end{array}$ & $\begin{array}{l}0.90 \\
0.86 \pm 0.02 \\
0.81 \pm 0.01 \\
0.88 \pm 0.01 \\
0.82 \pm 0.06 \\
0.80 \pm 0.01 \\
0.42 \pm 0.04\end{array}$ & $\begin{array}{l}3 \\
4 \\
1 \\
4 \\
2 \\
4 \\
3 \\
2 \\
2 \\
2 \\
1 \\
4 \\
6 \\
6\end{array}$ & $\begin{array}{l}0.95 \pm 0.03 \\
0.94 \pm 0.04 \\
0.82 \\
0.93 \pm 0.03 \\
0.87 \pm 0.03 \\
0.80 \pm 0.02 \\
0.88 \pm 0.04 \\
0.48 \pm 0.01 \\
0.46 \\
0.48 \\
0.44 \\
0.52 \pm 0.02 \\
0.63 \pm 0.06 \\
0.61 \pm 0.05\end{array}$ \\
\hline $\mathrm{GaSb}$ & $\begin{array}{l}n \\
n \\
p\end{array}$ & $\begin{array}{l}\mathrm{Au} \\
\mathrm{Au} \\
\mathrm{Au}\end{array}$ & $\begin{array}{l}300 \\
77 \\
300,77\end{array}$ & $\begin{array}{l}1 \\
3\end{array}$ & ohmic & $\begin{array}{l}2 \\
1\end{array}$ & $\begin{array}{l}0.61 \pm 0.03 \\
0.75\end{array}$ \\
\hline $\mathrm{InSb}$ & $\begin{array}{l}n \\
n \\
p\end{array}$ & $\begin{array}{l}\mathrm{Au} \\
\mathrm{Ag} \\
\mathrm{Au}\end{array}$ & $\begin{array}{l}77 \\
77 \\
77\end{array}$ & 1 & ohmic & $\begin{array}{l}2 \\
1\end{array}$ & $\begin{array}{l}0.17 \pm 01 \\
0.18\end{array}$ \\
\hline $\operatorname{In} P$ & $\begin{array}{l}n \\
n \\
n \\
n \\
n \\
p \\
p\end{array}$ & $\begin{array}{l}\mathrm{Au} \\
\mathrm{Au} \\
\mathrm{Cu} \\
\mathrm{Ag} \\
\mathrm{Ag} \\
\mathrm{Au} \\
\mathrm{Au}\end{array}$ & $\begin{array}{r}300 \\
77 \\
77 \\
300 \\
77 \\
300 \\
77\end{array}$ & 1 & $\begin{array}{l}0.52 \\
0.57\end{array}$ & $\begin{array}{l}3 \\
4 \\
1 \\
1 \\
1 \\
1 \\
1\end{array}$ & $\begin{array}{l}0.49 \pm 0.05 \\
0.56 \pm 0.04 \\
0.5 \\
0.54 \\
0.50 \\
0.76 \\
0.78\end{array}$ \\
\hline InAs & $\begin{array}{l}n \\
p\end{array}$ & $\underset{\mathrm{Au}}{\mathrm{Au}, \mathrm{Ag}, \mathrm{Al}}$ & $\begin{array}{c}300,77 \\
77\end{array}$ & 3 & ohmic & 4 & $0.47 \pm 0.01$ \\
\hline $\mathrm{Ge}$ & $\begin{array}{l}n \\
n \\
n\end{array}$ & $\begin{array}{l}\mathrm{Au} \\
\mathrm{Au} \\
\mathrm{Al}\end{array}$ & $\begin{array}{r}300 \\
77 \\
300\end{array}$ & & & $\begin{array}{l}1 \\
1 \\
2\end{array}$ & $\begin{array}{l}0.45 \\
0.50 \\
0.48 \pm 0.02\end{array}$ \\
\hline $\mathrm{SiC}$ (hexag) & $\begin{array}{l}n \\
n\end{array}$ & $\begin{array}{l}\mathrm{Au} \\
\mathrm{Al}\end{array}$ & $\begin{array}{l}300 \\
300\end{array}$ & & & $\begin{array}{l}4 \\
1\end{array}$ & $\begin{array}{l}1.95 \pm 0.1 \\
2.0\end{array}$ \\
\hline $\mathrm{AlSb}$ & $\begin{array}{l}p \\
p\end{array}$ & $\begin{array}{l}\mathrm{Au} \\
\mathrm{Au}\end{array}$ & $\begin{array}{r}300 \\
77\end{array}$ & 2 & $0.55 \pm 0.2$ & $\begin{array}{l}2 \\
2\end{array}$ & $\begin{array}{l}0.53 \pm 0.02 \\
0.59 \pm 0.02\end{array}$ \\
\hline AlAs & $\begin{array}{l}n \\
n\end{array}$ & $\begin{array}{l}\mathrm{Au} \\
\mathrm{Pt}\end{array}$ & $\begin{array}{l}300 \\
300\end{array}$ & $\begin{array}{l}2 \\
1\end{array}$ & $\begin{array}{l}1.2 \pm 0.1 \\
1.0\end{array}$ & & \\
\hline Diamond & $p$ & $\mathrm{Au}$ & $\sim 475$ & & & 2 & $1.35 \pm 0.10$ \\
\hline $\mathrm{BP}$ & $p$ & $\mathrm{Au}$ & 300 & 1 & 1.9 & 1 & 1.8 \\
\hline $\mathrm{BN}$ & $p$ & $\mathrm{Au}$ & 300 & & & 2 & $3.1 \pm 0.3$ \\
\hline $\mathrm{CdTe}$ & $n$ & $\begin{array}{l}\mathrm{Au} \\
\mathrm{Pt} \\
\mathrm{Ag} \\
\mathrm{Al}\end{array}$ & $\begin{array}{l}300 \\
300 \\
300 \\
300\end{array}$ & $\begin{array}{l}2 \\
1 \\
1 \\
1\end{array}$ & $\begin{array}{l}0.60 \pm 0.01 \\
0.58 \\
0.66 \\
0.76\end{array}$ & $\begin{array}{l}2 \\
1 \\
1\end{array}$ & $\begin{array}{l}0.71 \pm 0.02 \\
0.76 \\
0.81\end{array}$ \\
\hline
\end{tabular}

except for a sharply peaked anomaly in the vicinity of $x \approx 0.25$, where $\varphi_{B p}$ drops nearly to zero. It was thought that at this composition a superlattice might have been formed, but x-ray diffractometer studies failed to confirm this suspicion, and the cause of the anomaly is still not known. 


\section{DISCUSSION}

The theory of surface states has been treated by a number of authors, and is reviewed most recently by Koutecky ${ }^{5}$ and Antoncik. ${ }^{6}$ Despite the large variety of methods used to treat the problem, the general conclusion has been that Shockley type surface states occur in a narrow half-filled band approximately midway between conduction- and valence-band edges. The number of states in this band is of the order of the number of surface atoms. A detailed consideration of the effect of surface states on the metal-semiconductor contact has been given by Bardeen ${ }^{7}$ with the conclusion that the interface position of the Fermi level will be independent of the metal used provided the density of surface states is sufficiently high $\left(\gtrsim 10^{13} \mathrm{~cm}^{-2}\right)$. It appears that this condition is adequately met for the group IV and III-V semiconductors.

The experimental results shown in Table I indicate that the interface position of the Fermi level is fixed by surface states slightly below the center of the gap for a large number of these materials. This result, although not explicable in detail, is in keeping with the conclusions of the theoretical models mentioned above. In view of the highly idealized nature of these models, such agreement is quite remarkable. However, the materials InAs, InP, and GaSb were found to deviate significantly from the general pattern. The question arises as to whether it is possible to correlate these deviations with bulk properties of the materials.

It is convenient for this purpose to consider the III-V compounds in the light of the perturbation scheme of Herman. ${ }^{8}$ The crystal potential is written as

$$
V_{\text {crystal }}=V_{\text {IV }}+\lambda\left[V_{\text {sym }}+V_{\text {antisym }}\right],
$$

where the second term on the right is veiwed as a perturbation. The perturbation parameter $\lambda$ is equal to 0 for a group IV, 1 for a III-V, and 2 for a II-VI compound. For most materials $V_{\text {sym }}$, the symmetric component of the perturbing potential, is small. The perturbation of the band edges due to $V_{\text {antisym }}$ is zero in first order and all of the shift takes place in second order. The second-order perturbation energy for the conduction band is positive and that for the valence band negative.

The application of the second-order perturbation concept to zincblende structure materials has been considered at length by Cardona and Greenaway.9,10 The method consists basically of determining the energy gap at some point in the Brillouin zone [notably the (111) zone edge] for several zincblende materials of related sequence. (These sequences are classified as hori-

\footnotetext{
${ }^{5}$ J. Koutecky, Phys. Chem. Solids 14, 233 (1960).

6 E. Antoncik, Phys. Chem. Solids 21, 137 (1961).

${ }^{7}$ J. Bardeen, Phys. Rev. 71, 717 (1947).

8 F. Herman, J. Electronics 1, 103 (1955).

9 M. Cardona and D. L. Greenaway, Phys. Rev. 125, 129 (1963).

${ }_{10}$ M. Cardona and D. L. Greenaway, Phys. Rev. 131, 98 (1963).
}

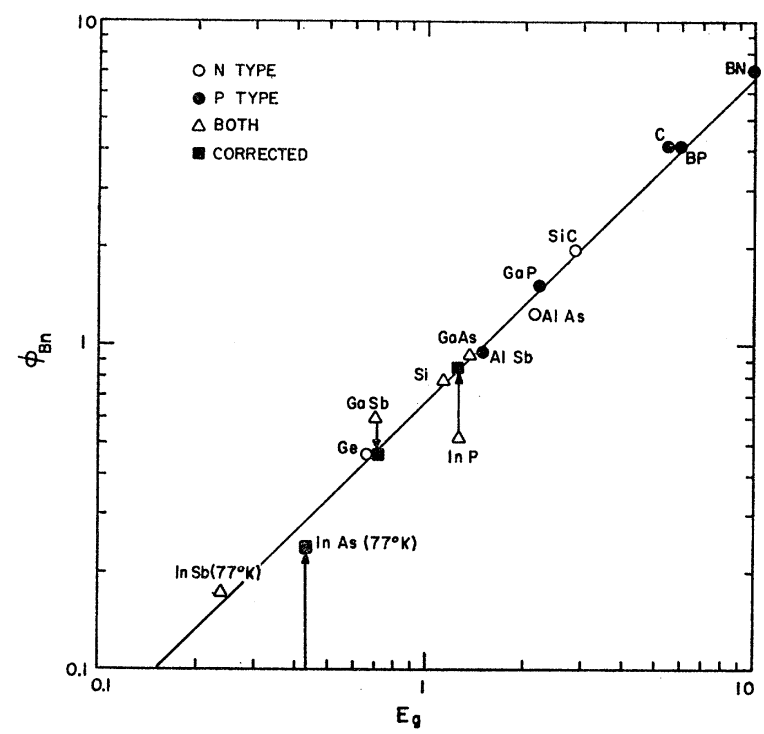

Fig. 1. Barrier heights (measured from the conduction band edge) for zincblende materials as a function of band gap. The corrected values were determined by subtracting the first-order perturbation energy from the measured value. (See text.)

zontal if the constituents are all from the same row of the periodic table and diagonal if they are from different rows.) The gaps are plotted versus $\lambda^{2}$, and the result should be a straight line if the shift is due to a secondorder perturbation.

For the horizontal sequences and light-element diagonal sequences, this procedure yields a straight-line fit to the experimental (111) gaps and the corresponding opposite members of the diagonal sequence have equal shifts. However, in the heavy-element diagonal sequences, the single-straight-line fit ceases to apply. Particularly InP, InAs, and GaSb are the offenders. These are just the materials in which Herman suggested that a first-order perturbation energy of the band edges could be expected. The result is a lowering of the GaSb gap and an increase in that of InAs and InP. An estimate of the magnitude of the first-order perturbation may be obtained from Fig. 2 of Ref. 9. If a line is drawn through SnGe roughly parallel to the Sn sequence, the deviations of InAs and GaSb may be read directly. The InP deviation can also be obtained by subtracting out the value for the Ge sequence. These are the only compounds for which notable deviations occur. It should be remarked that this interpretation would place the energy gap for cubic CdSe considerably below Cardona's extrapolated value, a prediction which should be checked experimentally.

If a first-order perturbation occurs in the band edges of at least one significant point in the Brillouin zone, it might be expected to produce a similar deviation in the energy of the surface state. Since the exact form of the wave function for the surface state is not known, the proportionality factor cannot be specified. However, since the perturbation is in first order it should change 
sign depending upon the sense of the diagonal sequence, i.e., as the group III or group V element is the heavy one. Experimentally this has been found to be the case. ${ }^{1}$

If the surface state energy is assumed to change in the same direction as the (111) band gap and by approximately the same amount, one can estimate the barrier heights to be expected for the three compounds, using $\phi_{B n}=2 E_{g} / 3$ as the unperturbed energy. The results of the procedure are shown in Fig. 1 together with the actual values for the other materials.

In spite of the empirical nature of this procedure, the results are in remarkable agreement with measured values. No doubt, with accurate wave functions for the surface state and an evaluation of the crystal potential which can be made in the light of present experimental band structure studies, a sophisticated and enlightening calculation can be performed. Meanwhile, it is believed that the present study indicates a direction in which further fruitful investigations can be made.

\section{ACKNOWLEDGMENTS}

The authors wish to express their appreciation to D. Reynolds, M. Lorentz, W. Allred, R. Willardson, D. Bolger, T. Benedict, R. Wentorf, R. Ruehrwein, and L. Bailey for supplying materials used in this study. Pol Duwez in performing the x-ray diffractometer measurements, and H. M. Simpson for fabricating the samples.

\title{
Lattice Dynamical Studies Using Absolute Measurements of the Lamb-Mössbauer Recoil-Free Fraction*
}

\author{
W. A. Steyert and R. D. Taylor \\ Los Alamos Scientific Laboratory, University of California, Los Alamos, Nerw Mexico
}

(Received 18 December 1963)

\begin{abstract}
Absolute values of the recoil-free fraction $f$ of the $14.4-\mathrm{keV} \gamma$ rays of $\mathrm{Fe}^{57}$ are reported at temperatures from 4 to $1050^{\circ} \mathrm{K}$. $\mathrm{Co}^{57}$, the parent of $\mathrm{Fe}^{57}$, is a dilute impurity in $\mathrm{Au}, \mathrm{Cu}, \mathrm{Ir}, \mathrm{Pd}, \mathrm{Pt}, \mathrm{Rh}$, and Ti. For intermediate temperatures the measured $f$ is consistent with the calculations of Visscher, and Maradudin and Flinn when the impurity-host coupling constant is taken to be about the same as the host-host coupling constant. At the highest temperatures, the $f$ 's of $\mathrm{Au}, \mathrm{Cu}$, and $\mathrm{Pd}$ fall off faster than simple theory would predict due to diffusion and anharmonicities. The results are compared with the anharmonic lattice theory of Maradudin and Flinn. Chemical and temperature-shift data are also reported.
\end{abstract}

\section{INTRODUCTION}

$T$ HE coupling between a Mössbauer nucleus and its surroundings enables the momentum of some of the $\gamma$ rays to be absorbed by a large number of atoms, hence, for these $\gamma$ rays there is almost no energy loss associated with the recoil. For this reason, studies of the Mössbauer emission provide an ideal method to investigate the nature of these coupling forces. The present study reports absolute measurements of $f$ (the fraction of recoil-free emissions) and of the temperature shift (the temperature-dependent energy shift of the $\gamma$ ray) in the case of an $\mathrm{Fe}^{57}$ nucleus as a dilute impurity in seven different host lattices. These hosts are elements in which the atomic size is very close to the atomic size of the Fe impurity; hence, we should expect the assumptions made in the Debye theory, and the refinements thereon by Visscher ${ }^{1}$ and by Maradudin and Flinn ${ }^{2}$ to have some validity. This is indeed the case for both the temperature shift and the $f$ values in the

\footnotetext{
* Work performed under the auspices of the U. S. Atomic Energy Commission.

1 W. M. Visscher, Phys. Rev. 129, 28 (1963).

2 A. A. Maradudin and P. A. Flinn, Phys. Rev. 126, 2059 (1962)
}

high-temperature region. At low temperatures the measured $f$ values deviate slightly from theory.

\section{EXPERIMENTAL METHOD AND RESULTS \\ General}

The method we employ is to measure the Mössbauer spectrum of a source made up of $\mathrm{Co}^{57}$ in a nonmagnetic host metal using a single line absorber. The observed resonance strength $F$ is

$$
F=\left[N(\infty)-N\left(v_{r}\right)\right] / N(\infty) B=f f_{B l} .
$$

$N(\infty)$ is the number of counts per unit time with the absorber moving at a sufficient velocity to prevent any resonance absorption, $N\left(v_{r}\right)$ is the number of counts per unit time at the velocity $v_{r}$ of the resonance peak, and $B$ is the background correction. $F$ is equal to the product of the recoil-free fraction of the source and the fractional absorption of these recoil free $\gamma$ rays by the absorber (called the "blackness" $f_{B l}$ ).

\section{Equipment}

For the low-temperature runs the source was mounted in a Dewar which had a pair of beryllium windows in 